\title{
Mammography screening - a recognised standard
}

\author{
Joanna Didkowska
}

Breast cancer is the most common global malignancy found in women and likewise so in Poland; newly diagnosed cases being respectively $\approx 1.7$ million and 17 thousand annually. For the last 30 years, population screening has been adopted in the developed world. In Poland, breast screening attendance is however around 45\%, what is still lower than in highly developed countries (above 70\%). Breast cancer mortality has also declined more slowly in Poland. Following the introduction of breast screening, the rapid decreases in mortality demonstrated in Western Europe and the USA prove its effectiveness. Observations and data accumulated over many years through screening have nevertheless generated debate regarding overdiagnosis and overtreatment of breast cancer. This issue has been summarised in the WHO Position Paper that recommends continuing breast screening whilst also ensuring that patients are able to make informed decisions.

NOWOTWORY J Oncol 2016; 66, 5: 418-421

Key words: breast cancer, population screening, overdiagnosis

Two opposing points of view were put forward during the debate on controversies arising around the issue of mammographic breast cancer screening, as organised by the Nowotwory Journal of Oncology: recognising screening as standard practice and doubts on the validity of such procedure.

Faced with the current state of knowledge, along with current practices in many countries and the WHO's position [1], population screening is undoubtedly a standard procedure at present in all highly developed countries of the world.

Assessment of population screening merits is based on literature review. Data on cancer incidence and mortality come from universally available epidemiological databases in both the world and Poland [2-5].

Discussions on this subject should start by presenting the scale of the problem. After lung cancer, breast cancer is the second most common malignancy in the world and the most common cancer in women; in 2012 cancer incidence was $\approx 1.7$ million what constituted $1 / 4$ of cancer in women. Breast cancer is the most common cancer in both developed and less well-developed countries with respective incidence rates of $\approx 883,000$ and 794,000 . Incidence rates greatly vary according to region: $\approx 10 / 10^{5}$ in some African countries (Gambia, Gabon, Rwanda) and Eastern Asia but are $100 / 10^{5}$ in the affluent countries of Europe (Belgium, Denmark) [1]. Breast cancer is responsible for half a million women's deaths worldwide (5 causes ranked at $15 \%$ ). It is a more frequent cause of death (20\%) in countries of low Human Development Index (HDI) compared to countries with a high HDI (17\%). Differences in mortality between regions are less than those for incidence, where the former varies from $6 / 10^{5}$ in the Far East to $20 / 10^{5}$ in Western Africa [2, 5].

In Poland, breast cancer is also the most common malignancy, constituting respectively $22 \%$ and $15 \%$ of cancer incidence and mortality. Over 17.2 thousand women must face up to receiving a breast cancer diagnosis, and 5.3 thousand die as a result. The problem of breast cancer in Poland intensifies when mortality rates are compared to those overall; 9\% mortality in young women aged 20-44 years and $14 \%$ in middle-aged women (45-64 years) are due to breast cancer $[3,4]$.

As breast cancer is such a serious problem, choosing the best strategy for prevention and dealing with its consequences becomes necessary. For many years a general scheme for optimal conduct regarding cancer has been: 
prevention, early detection and effective treatment. What can be achieved in the primary prevention of breast cancer?

Primary prevention is most effective in those diseases for which the risk factors are known so that modifying measures taken, can have a real impact on the behaviour of the population. In the case of breast cancer, women's risk factors are both constitutional (age at menarche, menopause) and lifestyle behaviour (weight, physical activity, alcohol consumption), together with decisions made on intimate matters (taking contraceptives, childbirth age, breast feeding, number of labours, taking Hormone Replacement Therapy - HRT). From the known risk factors, only exposure to HRT has been limited following publication of the Women's Health Initiative's findings [6]. In the USA, a threefold decrease in the number of HRT prescriptions over 2001-2003 resulted in immediate decrease of incidence in 2003, to $10 / 10^{5}$ women [7]. Data from Poland on HRT are very limited, and one can only expect that after the 1989 changes, coupled with pharmaceutical marketing and developments in pharmaceuticals, women born post World War II have easier access to such drugs. Despite the visible effects of the other aforementioned risk factors shown by ecological studies, they are difficult to modify and, quite probably, several need to be changed simultaneously. Therefore, perhaps secondary prevention (screening) may limit the societal consequences of breast cancer?

Poland was one of the countries that introduced screening in 2006, which compared to Western countries was 20 years behind. Participation of Polish women in screening programmes is still twice lower than in Western Europe and the USA. Currently, participation in screening programmes in Poland after 10 years stands at $45 \%$, whilst for the USA and Western Europe this ranges at 70-80\% [8]. The effectiveness of screening programmes started to be assessed after 30 years of observation; the 10 years observation period in Poland therefore precludes any assessment of efficiency or effectiveness.

Can the strategy for protecting women against breast cancer be solely based on the assumption that treating this disease is sufficiently effective? Breast cancer survival rates in highly developed countries exceeds $85 \%$. Poland's five year survival rates are around $10 \%$ lower; $74 \%$ of those diagnosed with the disease during 2005-2009, which is higher only in Latvia (71\%), Estonia, Lithuania and Slovakia (72\%) [9]. Can these differences be explained by the belated introduction of screening in Poland and the Baltic countries?

In those countries that introduced screening in the 1980-1990s, and where participation is high, survivals are also higher. If so, why are the merits of screening now been increasingly questioned. The criteria put forward by Wilson \& Junger in 1968 still remain in force for assessing screening. Breast cancer screening fulfils most of these criteria (an important health and societal problem; the possibility for curing and/or improved treatment outcomes at early stages; the preclinical phase for easy detection and treatment; appropriate and accepted tests being repeated from the time risk becomes recognised; defining a high risk sub-population; benefits exceeding the risk; population study costs not exceeding those for treatment). Doubts only become apparent when determining the natural disease-course history, where most of the reservations on breast cancer screening are directly related to this issue.

Introducing population-based screening was founded on the premise that breast cancer progression occurs in a 'linear' fashion. In such linear models, it is assumed that the tumour stably (uniformly) develops with time, creating a chain of events occurring in a defined and predictable manner, (starting from the atypical or in situ stages and terminating in metastases and death), and thus making an early diagnosis vital for decreasing mortality [10]. As from several years now, this linear model of breast cancer development is being cast aside in favour of models composed of different scenarios. An analysis of the actual disease course in several thousand so-affected patients allowed for creating a theoretical stochastic model, which shows that the way tumours progress can significantly impact on the advantages derived from screening [11]. Many studies indicate that a given tumour development follows various scenarios in accordance to its biology. A 'variation' model distinguishes three basic types of scenarios: indolent/regressive, slow and rapid, however the actual development course can be mixed. In the first case, the indolent/regressive, cell transformation is very slow or lesions can actually regress; so such women derive no benefit from being screened. The 'slow' scenario is identified with the classic linear model of breast cancer development; mortality rates become reduced as a result of screening in such cases. In those women where the disease course is 'rapid', there is a high likelihood of interval cancer where any benefits in screening are limited (Fig. 1).

Within the last decade the issue of overdiagnosing breast cancer has been debated regarding the screening, which is also linked to over-treatment. The key issue is overdiagnosis. The simplest and most intuitive definition of this term can be: diagnosing disease status, that would never give symptoms arising or lead to death. It seems likely that such terminology can only be correctly applied to those women at the 'indolent/regressive' scenarios of breast cancer. The above definition tacitly infers that there are high-probability methods for detecting persons with indolent/ /regressive tumours leading to overdiagnosis. However, it seems that the problem is that we lack sufficient knowledge, that could allow classifying women as having indolent/ /regressive tumours. Of course certain necessary conditions exists for defining the likelihood of developing one of the aforementioned scenarios, but the risk of committing an error is still large. 


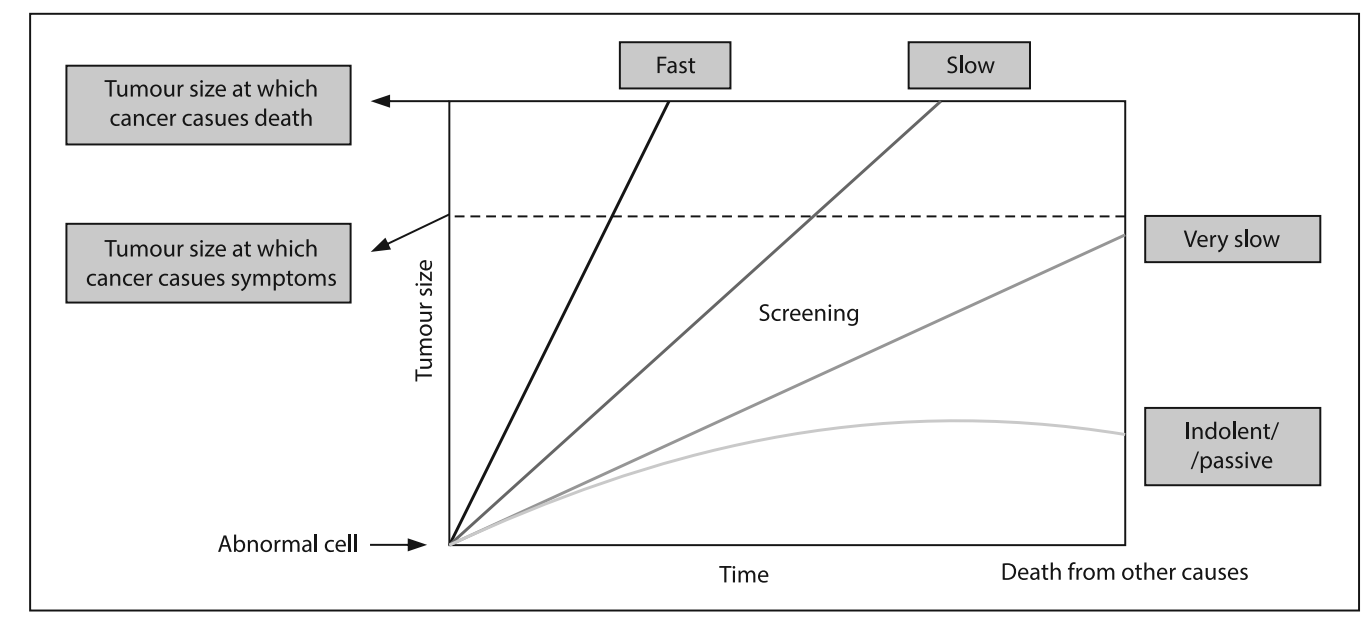

Figure 1. Theoretical scenarios of breast cancer development

Because many patients are overdiagnosed, (which is the main complaint levelled at screening), then, should they be treated, and if so, should this be considered as an overtreatment? The most frequent diagnosis, that is evoked as 'overdiagnosis' is Ductal carcinoma in situ. Some researchers and practioners wish to consider in situ cancer as an overdiagnosis. Yet the question on how to conduct treatment in such cases is debated in the most of the respected medical journals. Some recommend 30 minutes of daily physical exercise, but others say that the excellent outcomes of treating in situ cancer does not translate to equally favourable therapeutic outcomes without treatment, and thus treatment is indeed required [12].

A compelling argument for exercising caution about in situ cancer is the association between the incidence of discovering interval cancers with the incidence of detecting in situ cancer. A study by Duffy [13] demonstrated that in 1000 women taking part in screening, the increase in detecting Ductal carcinoma in situ from below 1 to over 2 is linked with an $11 \%$ decrease in detecting interval cancers. These studies have led to a functional relationship being established, indicating an inversely proportional relationship between detecting the incidence of in situ cancer and the incidence of invasive interval cancers.

A literature review assessing European screening studies by Paci et al., showed that reduced mortality in women taking part in screening varies from $38 \%$ (IBM sties) to $48 \%$ (clinical-control studies). Contemporaneously, overdiagnoses adjusted for lead time and breast cancer risk was estimated at being $1-10 \%$ (adjusted mean $=6.5 \%$ ). A balance of account put forward by researchers shows that for every 1000 women screened biannually aged, 50-69 years and up to 79 years of age, then it is possible to prevent mortality in 7-9 women, as compared to 30 such deaths without any screening at all, whilst 4 women are overdiagnosed [14].
The recommendations of the Guideline Development Group (GDG), that prepared the WHO position on breast cancer screening (according to GRADE methodology) with regards to a country's socio-economic development, advocate undertaking a mammography programme in those countries where a well developed national health service exists (including Poland), consisting of screening women aged 50-69 years, every 2 years. The GDG working group emphasises that the organisers of screening studies should have a strategic plan ready for informing women, in an objective and balanced fashion, about the benefits and risks of taking part in mammography screening, where women's decisions should agree with their preferred choices and be made with their full awareness [1].

I consider that the WHO position, best represents today's knowledge and most importantly emphasises the empowering of women. It is the woman who should decide for herself whether to be screened on the basis of objective information, and her participation should be accommodated under a caring and hospitable environment. Breast cancer screening is a standard procedure in all developed countries and it is hoped that this likewise remains the case in Poland.

Conflict of interest: none declared

\section{Joanna Didkowska, MD, PhD}

Department of Epidemiology and Cancer Prevention

Maria Sklodowska-Curie Memorial Cancer Center

and Institute of Oncology

Roentgena 5, 02-781 Warszawa, Poland

e-mail:joanna.didkowska@coi.pl

Received \& Accepted: 30 Jun 2016

Based on the presentation at the IV Annual Conference of the Nowotwory Journal of Oncology, 'Oncological Debates', held in Warszawa, 8-9 ${ }^{\text {th }}$ April 2016 


\section{References}

1. WHO position paper on mammography screening. Geneva: WHO, 2014.

2. Ferlay J, Soerjomataram I, Ervik M et al. GLOBOCAN 2012 v1.0, Cancer Incidence and Mortality Worldwide: IARC CancerBase No. 11. Lyon: International Agency for Research on Cancer, 2013. http://globocan.iarc.fr accessed on 31/03/2016.

3. Didkowska J, Wojciechowska U. Nowotwory złośliwe w Polsce w 2013 roku. Warszawa:Centrum Onkologii_-Instytut im. M. Skłodowskiej-Curie, 2015.

4. Wojciechowska U, Didkowska. Zachorowania i zgony na nowotwory złośliwe w Polsce. Centrum Onkologii — Instytut im. Marii Skłodowskiej-Curie: Krajowy Rejestr Nowotworów. Dostępne na stronie http:// //onkologia.org.pl/raporty/, acessed on 30/03/2016.

5. World Health Organization, health statistics and information systems, mortality database http://www-dep.iarc.fr/WHOdb/WHOdb.htm (accessed on 30/03/2016).

6. Risks and benefits of estrogen plus progestin in healthy postmenopausal women: principal results from the Women's Health Initiative randomized controlled trial. JAMA 2002; 288: 321-333.

7. Ravdin $\mathrm{PM}$, Cronin $\mathrm{CA}$, Howlader $\mathrm{N}$ et al. The decrease in breast-cancer incidence in 2003 in the United States. NEng/JMed 2007; 356: 1670-1674.
8. IARC handbooks of cancer prevention. Vol. 7: Breast cancer screening. Lyon: IARC Press, 2002.

9. Alemanii $\mathrm{C}$, Weir HK, Carreira $\mathrm{H}$ et al. Global surveillance of cancer survival 1995-2009: analysis of individual data for 25676887 patients from 279 population-based registries in 67 countries (CONCORD-2). Lancet 2015; 385: 977-1010.

10. Duffy S, Hill C, Esteve J (eds). Quantitative methods for the evaluation of cancer screening. London: Arnold Publishers, 2001.

11. Esserman LJ, Thompson IM, Reid B et al. Addressing overdiagnosis and overtreatment in cancer: a prescription for change. Lancet 2014; 15: e234-e242.

12. Merrill AL, Esserman L, Morrow M. Ductal carcinoma in situ. N Engl J Med 2016; 374: 390-392.

13. Duffy SW, Dibden A, Michalopoulos D et al. Screen detection of ductal carcinoma in situ and subsequent incidence of invasive interval breast cancers: a retrospective population-based study. Lancet Oncology 2016; 17: 109-114.

14. Paci $\mathrm{E}$, Broeders $\mathrm{H}$, Hofving $\mathrm{S}$ et al. European breast cancer screening outcomes: a first balance sheet of the benefits and harms. Cancer Epidemiol Biomarkers Prev 2014; 23: 1159-1163. 